\title{
PENYELESAIAN PERSAMAAN NONLINIER DENGAN METODE MODIFIKASI BAGI DUA
}

\author{
ELSA JUMIASRI, SUSILA BAHRI, BUKTI GINTING \\ Program Studi Matematika, \\ Fakultas Matematika dan Ilmu Pengetahuan Alam, Universitas Andalas, \\ Kampus UNAND Limau Manis Padang, Indonesia. \\ elsa.jumiastri@ymail.com
}

\begin{abstract}
Dalam tulisan ini, akar suatu persamaan nonlinier ditentukan dengan Metode Modifikasi Bagi Dua. Beberapa kasus yang muncul karena perbedaan nilai fungsi pada kedua titik ujung interval dibahas diperoleh bahwa $a_{k}<x_{k}<b_{k}$. Metode ini memerlukan iterasi yang lebih sedikit bila dibandingkan dengan Metode Bagi Dua.

Kata Kunci: Metode Bagi Dua, Metode Modifikasi Bagi Dua, Persamaan Nonlinier
\end{abstract}

\section{Pendahuluan}

Masalah pencarian aproksimasi akar dari sebuah persamaan nonlinier sering ditemukan di berbagai bidang sains dan teknik. Akar-akar persamaan nonlinier tersebut tidak mudah ditemukan secara analitik kecuali pada kasus-kasus sederhana. Oleh karena itu, penyelesaian masalah pencarian akar persamaan nonlinier memerlukan pendekatan numerik. Penentuan akar $x$ dari persamaan $f(x)=0$ yang merupakan aplikasi algoritma numerik tersebut, diperoleh melalui satu atau beberapa iterasi yang akan berakhir sesuai dengan kriteria penghentian iterasi yang telah ditetapkan.

Ada beberapa metode yang dapat digunakan dalam penentuan akar dari persamaan nonlinier. Metode Bagi Dua merupakan metode numerik paling sederhana di antara metode-metode numerik lainnya. Metode ini termasuk metode yang robust atau tangguh. Hal ini berarti, meskipun metode tersebut memiliki ide yang sangat sederhana namun akar persamaannya selalu dapat ditemukan [5]. Metode ini juga selalu konvergen ke nilai eksak meskipun konvergensinya relatif lambat. Untuk mengatasi konvergensi yang lambat tersebut dapat digunakan Metode Modifikasi Bagi Dua yang merupakan modifikasi dari Metode Bagi Dua. Menurut S. Tanakan [6], Metode Modifikasi Bagi Dua lebih cepat konvergensinya daripada Metode Bagi Dua.

\section{Landasan teori}

\subsection{Galat}

Metode numerik selalu menghasilkan nilai aproksimasi (hampiran) dari nilai eksak. Nilai aproksimasi inilah yang memunculkan galat atau error. Galat $(\epsilon)$ didefinisikan sebagai

$$
\epsilon=x-x^{*},
$$


dimana $x$ dan $x^{*}$ berturut-turut merupakan nilai eksak dan nilai aproksimasi.

\subsection{Persamaan Nonlinier}

Persamaan nonlinier dinyatakan sebagai $f(x)=0$ dimana fungsi $f$ pada persamaan tersebut berupa polinomial berderajat $n>1$ atau persamaan yang mengandung fungsi trigonometri, logaritma, atau eksponen. Penyelesaian persamaan nonlinier adalah penentuan akar-akar persamaan nonlinier, dimana nilai akar $x$ menyebabkan nilai $f(x)=0$. Dengan kata lain akar persamaan $f(x)=0$ adalah titik potong antara kurva $f(x)$ dan sumbu $x[1]$.

\subsection{Teorema Nilai Antara}

Teorema 2.1. [2] Jika $f$ kontinu pada $[a, b]$ dan $L$ sebuah bilangan antara $f(a)$ dan $f(b)$, maka terdapat sebuah bilangan $c \in(a, b)$ sedemikian sehingga $f(c)=L$.

\subsection{Teorema Bolzano}

Teorema 2.2. [3] Jika $f$ kontinu pada $[a, b]$ dimana $f(a) \geq 0 \geq f(b)$, maka terdapat sebuah bilangan $c \in(a, b)$ sedemikian sehingga $f(c)=0$.

\subsection{Metode Bagi Dua}

Pada Metode Bagi Dua diketahui interval $[a, b]$ yang memuat akar dimana $f(a) . f(b)<0$. Untuk menghampiri akar tersebut, ditentukan titik tengah $x=\frac{a+b}{2}$ yang membagi interval $[a, b]$ menjadi dua buah subinterval sama panjang, yaitu $[a, x]$ dan $[x, b]$. Jika $f(a) . f(x)<0$ maka menurut Teorema Bolzano interval $[a, x]$ memuat akar dari $f(x)=0$ dan $x=b$. Sebaliknya, jika $f(x) . f(b)<0$ maka interval $[x, b]$ memuat akar dari $f(x)=0$ dan $x=a$ sehingga diperoleh interval baru $[a, b][2]$.Proses diulangi hingga diperoleh nilai akar yang sesuai dengan kriteria penghentian iterasi yang ditetapkan yaitu $\left|f\left(x_{n}\right)\right| \leq \epsilon$ dimana $\epsilon$ merupakan galat yang ditentukan.

\section{Metode Modifikasi Bagi Dua}

Misalkan fungsi $f$ kontinu dan terdefinisi pada $a, b$ dimana $f(a) . f(b)<0$. Pertama, buat $a_{1}=a$ dan $b_{1}=b$. Untuk suatu bilangan bulat $k \geq 1$, tentukan titik tengah interval yaitu $c_{k}=\left(a_{k}+b_{k}\right) / 2$ sehingga diperoleh sebuah sub interval baru $\left[a_{k}^{*}, b_{k}^{*}\right]$ dengan:

$$
\left(a_{k}^{*}, b_{k}^{*}\right)=\left\{\begin{array}{l}
\left(a_{k}, c_{k}\right), \text { jika } f\left(a_{k}\right) \cdot f\left(c_{k}\right)<0 ; \\
\left(c_{k}, b_{k}\right), \text { jika } f\left(c_{k}\right) \cdot f\left(b_{k}\right)<0 .
\end{array}\right.
$$

Kemudian persamaan garis lurus dari titik $\left(a_{k}^{*}, f\left(a_{k}^{*}\right)\right)$ dan $\left(b_{k}^{*}, f\left(b_{k}^{*}\right)\right)$ adalah sebagai berikut:

$$
y=m x+c,
$$


dimana

$$
\begin{aligned}
m & =\frac{f\left(b_{k}^{*}\right)-f\left(a_{k}^{*}\right)}{b_{k}^{*}-a_{k}^{*}}, \\
c & =f\left(b_{k}^{*}\right)-m \cdot b_{k}^{*} \text { atau } c=f\left(a_{k}^{*}\right)-m . a_{k}^{*} .
\end{aligned}
$$

Oleh karena itu, perpotongan garis lurus tersebut pada sumbu $x$ adalah pada titik $x_{k}=-\frac{c}{m}$, yaitu:

$$
\begin{aligned}
& x_{k}=b_{k}^{*}-f\left(b_{k}^{*}\right) \cdot \frac{b_{k}^{*}-a_{k}^{*}}{f\left(b_{k}^{*}\right)-f\left(a_{k}^{*}\right)}, \\
& x_{k}=a_{k}^{*}-f\left(a_{k}^{*}\right) \cdot \frac{b_{k}^{*}-a_{k}^{*}}{f\left(b_{k}^{*}\right)-f\left(a_{k}^{*}\right)} .
\end{aligned}
$$

Kemudian untuk iterasi selanjutnya pilih sub interval baru, yaitu:

$$
\left(a_{k+1}, b_{k+1}\right)=\left\{\begin{array}{l}
\left(a_{k}^{*}, x_{k}\right), \text { jika } f\left(a_{k}^{*}\right) \cdot f\left(x_{k}\right)<0, \\
\left(x_{k}, b_{k}^{*}\right), \text { jika } f\left(x_{k}\right) \cdot f\left(b_{k}^{*}\right)<0
\end{array}\right.
$$

Proses dilanjutkan hingga interval cukup kecil atau solusi aproksimasi tertutup terhadap solusi eksak.

Algoritma Metode Modifikasi Bagi Dua untuk memperoleh solusi dari persamaan nonlinier $f(x)=0$ pada suatu interval $[a, b]$ secara ringkas dapat dinyatakan sebagai berikut:

\section{Algoritma Modifikasi Bagi Dua}

(1) Tetapkan nilai $f(x), a, b, \epsilon$ dan iterasi maksimum $m$

(2) $k \leftarrow 1$

$$
\begin{aligned}
& a_{k} \leftarrow a \\
& b_{k} \leftarrow b \\
& c_{k} \leftarrow \frac{a_{k}+b_{k}}{2} .
\end{aligned}
$$

(3) Tentukan sub interval $\left[a_{k}^{*}, b_{k}^{*}\right]$ dengan:

$$
\left(a_{k}^{*}, b_{k}^{*}\right)=\left\{\begin{array}{l}
\left(a_{k}, c_{k}\right), \text { jika } f\left(a_{k}\right) \cdot f\left(c_{k}\right)<0 \\
\left(c_{k}, b_{k}\right), \text { jika } f\left(c_{k}\right) \cdot f\left(b_{k}\right)<0 .
\end{array}\right.
$$

(4) $x_{k} \leftarrow a_{k}^{*}-f\left(a_{k}^{*}\right) \cdot \frac{b_{k}^{*}-a_{k}^{*}}{f\left(b_{k}^{*}\right)-f\left(a_{k}^{*}\right)}$ atau $x_{k} \leftarrow b_{k}^{*}-f\left(b_{k}^{*}\right) \cdot \frac{b_{k}^{*}-a_{k}^{*}}{f\left(b_{k}^{*}\right)-f\left(a_{k}^{*}\right)}$

(5) Jika $\left|f\left(x_{k}\right)\right|<\epsilon$ maka diperoleh nilai akar $x_{k}$, selesai.

Jika tidak, maka tentukan:

$$
\left(a_{k+1}, b_{k+1}\right)=\left\{\begin{array}{l}
\left(a_{k}^{*}, x_{k}\right), \text { jika } f\left(a_{k}^{*}\right) \cdot f\left(x_{k}\right)<0, \\
\left(x_{k}, b_{k}^{*}\right), \text { jika } f\left(x_{k}\right) \cdot f\left(b_{k}^{*}\right)<0 .
\end{array}\right.
$$

Selanjutnya kembali ke langkah 2 dan buat $k=k+1$.

Dari algoritma Modifikasi Bagi Dua, diperoleh teorema-teorema berikut:

Teorema 3.1. [6] Misalkan $f$ sebuah fungsi kontinu dan terdefinisi pada $[a, b]$ dengan $f(a) . f(b)<0$. Metode Modifikasi Bagi Dua menghasilkan sebuah barisan $\left\{x_{n}\right\}_{n=1}^{\infty}$ dengan

$$
a_{k}<x_{k}<b_{k} \text { untuk } k \geq 1
$$


Bukti. Karena $f(a) . f(b)<0$, terdapat dua kemungkinan kasus:

Kasus 1. $f\left(a_{k}\right)<0$ dan $f\left(b_{k}\right)>0$.

Berdasarkan persamaan (3.1.1) diperoleh sub interval $\left[a_{k}^{*}, b_{k}^{*}\right]$, yaitu:

(i) Jika $f\left(a_{k}\right) \cdot f\left(c_{k}\right)<0$ maka $a_{k}^{*}=a_{k}, b_{k}^{*}=c_{k}$ dan $f\left(b_{k}^{*}\right)>0$ sehingga diperoleh

$$
f\left(b_{k}^{*}\right) \cdot \frac{b_{k}^{*}-a_{k}^{*}}{f\left(b_{k}^{*}\right)-f\left(a_{k}^{*}\right)}>0
$$

Kemudian

$$
x_{k}=b_{k}^{*}-f\left(b_{k}^{*}\right) \cdot \frac{b_{k}^{*}-a_{k}^{*}}{f\left(b_{k}^{*}\right)-f\left(a_{k}^{*}\right)}<b_{k}^{*}<b_{k} .
$$

Karena

$$
f\left(a_{k}^{*}\right) \cdot \frac{b_{k}^{*}-a_{k}^{*}}{f\left(b_{k}^{*}\right)-f\left(a_{k}^{*}\right)}<0
$$

maka diperoleh

$$
x_{k}=a_{k}^{*}-f\left(a_{k}^{*}\right) \cdot \frac{b_{k}^{*}-a_{k}^{*}}{f\left(b_{k}^{*}\right)-f\left(a_{k}^{*}\right)}>a_{k}^{*}=a_{k} .
$$

Oleh karena itu,

$$
a_{k}<x_{k}<b_{k} .
$$

(ii) Jika $f\left(c_{k}\right) \cdot f\left(b_{k}\right)<0$ maka $a_{k}^{*}=c_{k}, b_{k}^{*}=b_{k}$ dan $f\left(a_{k}^{*}\right)<0$ sehingga diperoleh

$$
f\left(b_{k}^{*}\right) \cdot \frac{b_{k}^{*}-a_{k}^{*}}{f\left(b_{k}^{*}\right)-f\left(a_{k}^{*}\right)}>0 .
$$

Kemudian

$$
x_{k}=b_{k}^{*}-f\left(b_{k}^{*}\right) \cdot \frac{b_{k}^{*}-a_{k}^{*}}{f\left(b_{k}^{*}\right)-f\left(a_{k}^{*}\right)}<b_{k}^{*}=b_{k} .
$$

Karena

$$
f\left(a_{k}^{*}\right) \cdot \frac{b_{k}^{*}-a_{k}^{*}}{f\left(b_{k}^{*}\right)-f\left(a_{k}^{*}\right)}<0
$$

maka diperoleh

$$
x_{k}=a_{k}^{*}-f\left(a_{k}^{*}\right) \cdot \frac{b_{k}^{*}-a_{k}^{*}}{f\left(b_{k}^{*}\right)-f\left(a_{k}^{*}\right)}>a_{k}^{*}>a_{k} .
$$

Oleh karena itu,

$$
a_{k}<x_{k}<b_{k} .
$$

Kasus 2. $f\left(a_{k}\right)>0$ dan $f\left(b_{k}\right)<0$

Berdasarkan persamaan (3.1) diperoleh sub interval $\left[a_{k}^{*}, b_{k}^{*}\right]$, yaitu: 
Elsa Jumiastri dkk

(i) Jika $f\left(a_{k}\right) \cdot f\left(c_{k}\right)<0$ maka $a_{k}^{*}=a_{k}, b_{k}^{*}=c_{k}$ dan $f\left(b_{k}^{*}\right)<0$ sehingga diperoleh

$$
f\left(b_{k}^{*}\right) \cdot \frac{b_{k}^{*}-a_{k}^{*}}{f\left(b_{k}^{*}\right)-f\left(a_{k}^{*}\right)}>0
$$

Kemudian

$$
x_{k}=b_{k}^{*}-f\left(b_{k}^{*}\right) \cdot \frac{b_{k}^{*}-a_{k}^{*}}{f\left(b_{k}^{*}\right)-f\left(a_{k}^{*}\right)}<b_{k}^{*}<b_{k} .
$$

Karena

$$
f\left(a_{k}^{*}\right) \cdot \frac{b_{k}^{*}-a_{k}^{*}}{f\left(b_{k}^{*}\right)-f\left(a_{k}^{*}\right)}<0
$$

maka diperoleh

$$
x_{k}=a_{k}^{*}-f\left(a_{k}^{*}\right) \cdot \frac{b_{k}^{*}-a_{k}^{*}}{f\left(b_{k}^{*}\right)-f\left(a_{k}^{*}\right)}>a_{k}^{*}=a_{k} .
$$

Oleh karena itu,

$$
a_{k}<x_{k}<b_{k} .
$$

(ii) Jika $f\left(c_{k}\right) \cdot f\left(b_{k}\right)<0$ maka $a_{k}^{*}=c_{k}, b_{k}^{*}=b_{k}$ dan $f\left(a_{k}^{*}\right)>0$ sehingga diperoleh

$$
f\left(b_{k}^{*}\right) \cdot \frac{b_{k}^{*}-a_{k}^{*}}{f\left(b_{k}^{*}\right)-f\left(a_{k}^{*}\right)}>0 .
$$

Kemudian

$$
x_{k}=b_{k}^{*}-f\left(b_{k}^{*}\right) \cdot \frac{b_{k}^{*}-a_{k}^{*}}{f\left(b_{k}^{*}\right)-f\left(a_{k}^{*}\right)}<b_{k}^{*}=b_{k} .
$$

Karena

$$
f\left(a_{k}^{*}\right) \cdot \frac{b_{k}^{*}-a_{k}^{*}}{f\left(b_{k}^{*}\right)-f\left(a_{k}^{*}\right)}<0
$$

maka diperoleh

$$
x_{k}=a_{k}^{*}-f\left(a_{k}^{*}\right) \cdot \frac{b_{k}^{*}-a_{k}^{*}}{f\left(b_{k}^{*}\right)-f\left(a_{k}^{*}\right)}>a_{k}^{*}>a_{k} .
$$

Oleh karena itu,

$$
a_{k}<x_{k}<b_{k}
$$

Teorema 3.2. [6] Jika $a_{n}$ dan $b_{n}$ memenuhi persamaan (3.1) maka

$$
b_{n+1}-a_{n+1} \leq \frac{b-a}{2^{n}} \text { untuk } n \geq 1 .
$$

Bukti. Pembuktian menggunakan Induksi Matematika.

Langkah Basis. Untuk $n=1$ diperoleh:

$$
b_{2}-a_{2} \leq \frac{b-a}{2}
$$


Langkah Induksi. Asumsikan bahwa (3.3) berlaku untuk $n=k-1$, diperoleh

$$
b_{k}-a_{k} \leq \frac{b-a}{2^{k-1}}
$$

dapat ditunjukkan bahwa untuk $n=k$ berlaku

$$
b_{k+1}-a_{k+1} \leq \frac{b_{k}-a_{k}}{2} \leq \frac{b-a}{\frac{2^{k-1}}{2}}=\frac{b-a}{2^{k}} .
$$

Teorema 3.3. [6] Misalkan fungsi $f$ kontinu dan terdefinisi pada $[a, b]$ dimana $f(a) . f(b)<0$. Metode Modifikasi Bagi Dua menghasilkan sebuah barisan $\left\{x_{n}\right\}_{n=1}^{\infty}$ yang mengaproksimasi akar $x^{*}$ pada $f$ dengan

$$
\left|x_{n}-x^{*}\right|<\frac{b-a}{2^{n+1}} \text { untuk } n \geq 1 .
$$

Oleh karena itu barisan $\left\{x_{n}\right\}_{n=1}^{\infty}$ konvergen ke akar $x^{*}$, yaitu

$$
\lim _{n \rightarrow \infty} x_{n}=x_{*} .
$$

Bukti. Dari algoritma Metode Modifikasi Bagi Dua untuk sebarang $n>1$ diperoleh dua kasus:

Kasus 1. Jika $f\left(a_{n}\right) . f\left(c_{n}\right)<0$, maka $a_{n}<x_{n}<c_{n}<b_{n}$ dan $a_{n}<x^{*}<c_{n}<b_{n}$. Sehingga diperoleh

$$
x_{n}-b_{n}<x_{n}-c_{n}<x_{n}-x^{*}<x_{n}-a_{n} .
$$

Karena $x_{n}<c_{n}$, maka $x_{n}-a_{n}<c_{n}-a_{n}=\frac{b_{n}-a_{n}}{2}$. Selanjutnya karena $a_{n}<x_{n}$ maka diperoleh $a_{n}-c_{n}<x_{n}-c_{n}$, sehingga

$$
-\frac{\left(b_{n}-a_{n}\right)}{2}<x_{n}-c_{n}<x_{n}-x^{*}<\frac{b_{n}-a_{n}}{2} .
$$

Oleh karena itu, dari Teorema 3.1 diperoleh

$$
\left|x_{n}-x^{*}\right|<\frac{b_{n}-a_{n}}{2}=\frac{b-a}{2^{n+1}} .
$$

Kasus 2. Jika $f\left(c_{n}\right) . f\left(b_{n}\right)<0$, maka $a_{n}<c_{n}<x_{n}<b_{n}$ dan $a_{n}<c_{n}<x^{*}<b_{n}$, sehingga diperoleh

$$
x_{n}-b_{n}<x_{n}-x^{*}<x_{n}-c_{n}<x_{n}-a_{n} .
$$

Karena $c_{n}<x_{n}$ maka diperoleh

$$
c_{n}-b_{n}<x_{n}-b_{n},
$$

atau

$$
-\frac{\left(b_{n}-a_{n}\right)}{2}<x_{n}-b_{n}<x_{n}-x^{*}
$$

Selanjutnya karena $x_{n}<b_{n}$ dan $c_{n}<x^{*}$, diperoleh $x_{n}-x^{*}<b_{n}-x^{*}$ dan $b_{n}-x^{*}<b_{n}-c_{n}$, sehingga

$$
x_{n}-x^{*}<b_{n}-c_{n}=\frac{\left(b_{n}-a_{n}\right)}{2} .
$$




\begin{tabular}{|c|c|c|c|c|}
\hline Persamaan Nonlinier & Interval & $\begin{array}{c}\text { Banyak Iterasi } \\
\text { Metode } \\
\text { Bagi Dua }\end{array}$ & $\begin{array}{c}\text { Banyak Iterasi } \\
\text { Metode Modifikasi } \\
\text { Bagi Dua }\end{array}$ & Akar \\
\hline$f_{1}(x)=10 x e^{-x^{2}}-1$ & {$[-1,1]$} & 26 & 5 & 0.10102585 \\
$f_{2}(x)=\sin x-\frac{x}{2}$ & {$[-3,5]$} & 29 & 8 & 1.89549427 \\
\hline
\end{tabular}

Tabel 1. Perbandingan Banyak Iterasi Metode Bagi Dua dan Metode Modifikasi Bagi Dua

Maka akan diperoleh

$$
-\frac{\left(b_{n}-a_{n}\right)}{2}<x_{n}-x^{*}<\frac{b_{n}-a_{n}}{2} .
$$

Selanjutnya dari Teorema 3.1 diperoleh

$$
\left|x_{n}-x^{*}\right|<\frac{b_{n}-a_{n}}{2}=\frac{b-a}{2^{n+1}} .
$$

Dari kedua kasus diatas, berlaku

$$
-\lim _{n \rightarrow \infty} \frac{b-a}{2^{n+1}}<\lim _{n \rightarrow \infty} x_{n}-x^{*}<\lim _{n \rightarrow \infty} \frac{b-a}{2^{n+1}} .
$$

Karena $\lim _{n \rightarrow \infty} \frac{b-a}{2^{n+1}}=0$, maka dari teorema Apit diperoleh

$$
\lim _{n \rightarrow \infty} x_{n}=x^{*} .
$$

Berikut perbandingan jumlah iterasi yang diperoleh dalam pencarian akar persamaan nonlinier dengan menggunakan Metode Bagi Dua dan Metode Modifikasi Bagi Dua dimana $\epsilon=1.10^{-7}$.

Dari Tabel 1, terlihat bahwa jumlah iterasi yang dibutuhkan untuk mencari akar persamaan nonlinier dengan menggunakan Metode Bagi Dua lebih banyak daripada jumlah iterasi yang dibutuhkan oleh Metode Modifikasi Bagi Dua [6].

\section{Kesimpulan}

Pada tulisan ini telah ditunjukkan bahwa metode Modifikasi Bagi Dua dapat digunakan untuk mencari akar-akar persamaan nonlinier. Selanjutnya juga telah ditunjukkan bahwa metode Modifikasi Bagi Dua lebih cepat konvergen dari pada Metode Bagi Dua.

\section{Ucapan Terima kasih}

Penulis mengucapkan terima kasih kepada Bapak Budi Rudianto, M.Si, Bapak Narwen, M.Si dan Bapak Dr. Mahdhivan Syafwan yang telah memberikan masukan dan saran dalam penyempurnaan penulisan artikel ini.

\section{Daftar Pustaka}

[1] Basuki. A dan Ramadijanti. N. 2004. Metode Numerik sebagai Algoritma Komputasi. Diktat Kuliah D4, PEN-ITS. 
Penyelesaian Persamaan Nonlinier dengan Metode Modifikasi Bagi Dua 75

[2] J.H. Mathews and K.D. Fink. 1999. Numerical Methods Using MATLAB, 3rd Edition.

[3] Körner, T. W. 2003. Analysis I . Lecture Note

[4] Munir, Rinaldi. 2008. Metode Numerik, edisi kedua. Informatika, Bandung.

[5] Supardi (tanpa tahun).Bab II Pencarian Akar Persamaan Non Linier. Bahan Ajar UNY, Yogyakarta.

[6] Tanakan.S. A New Algorithm of Modified Bisection Method for Nonlinear Equation. Applied Mathematical Sciences textbf7 (2013) (123) : 6107 - 6114 